\title{
Monitoring metabolic reactions in Staphylococcus epidermidis exposed to silicon nitride using in situ time- lapse Raman spectroscopy
}

Francesco Boschetto

Tetsuya Adachi

Satoshi Horiguchi

Danny Fainozzi

Fulvio Parmigiani

Elia Marin

Wenliang Zhu

Bryan J. McEntire

Toshiro Yamamoto

Narisato Kanamura

Osam Mazda

Eriko Ohgitani

Giuseppe Pezzotti 


\title{
Monitoring metabolic reactions in Staphylococcus epidermidis exposed to silicon nitride using in situ time-lapse Raman spectroscopy
}

\author{
Francesco Boschetto, ${ }^{\mathrm{a}, \mathrm{b}}$ Tetsuya Adachi, ${ }^{\mathrm{b}, \mathrm{c}}$ Satoshi Horiguchi, ${ }^{\mathrm{b}, \mathrm{c}}$ Danny Fainozzi, ${ }^{\mathrm{d}}$ Fulvio Parmigiani, ${ }^{\mathrm{d}}$ \\ Elia Marin, ${ }^{\mathrm{a}, \mathrm{c}}$ Wenliang Zhu, ${ }^{\mathrm{a}}$ Bryan J. McEntire, ${ }^{\mathrm{e}}$ Toshiro Yamamoto, ${ }^{\mathrm{c}}$ Narisato Kanamura, ${ }^{\mathrm{c}}$ \\ Osam Mazda, ${ }^{b}$ Eriko Ohgitani, ${ }^{b}$ and Giuseppe Pezzotti $i^{a, b, f, g, h, \star}$ \\ ${ }^{a} K y o t o$ Institute of Technology, Ceramic Physics Laboratory, Kyoto, Japan \\ ${ }^{b}$ Kyoto Prefectural University of Medicine, Department of Immunology, Kyoto, Japan \\ ${ }^{c} K y o t o$ Prefectural University of Medicine, Graduate School of Medical Science, Department of Dental Medicine, Kyoto, Japan \\ 'University of Trieste, Department of Physics, Trieste, Italy \\ ${ }^{\mathrm{e}}$ Amedica Corporation, Salt Lake City, Utah, United States \\ 'Tokyo Medical University, Department of Orthopedic Surgery, Tokyo, Japan \\ gOsaka University, The Center for Advanced Medical Engineering and Informatics, Osaka, Japan \\ ${ }^{\mathrm{h}}$ The Center for Advanced Insect Research Promotion (CAIRP), Kyoto Institute of Technology, Kyoto, Japan
}

\begin{abstract}
Staphylococcus epidermidis (S. epidermidis) is one of the leading nosocomial pathogens, particularly associated with periprosthetic infections of biomedical implants. Silicon nitride $\left(\mathrm{Si}_{3} \mathrm{~N}_{4}\right)$, a nonoxide biomaterial widely used in spinal implants, has shown bacteriostatic effects against both gram-positive and gram-negative bacteria; however, the physicochemical interactions between $\mathrm{Si}_{3} \mathrm{~N}_{4}$ and bacteria yet remain conspicuously unexplored. In situ time-lapse Raman spectroscopic experiments were conducted by exposing S. epidermidis for 12,24 , and $48 \mathrm{~h}$ to $\mathrm{Si}_{3} \mathrm{~N}_{4}$ substrates to understand the evolution of bacterial metabolism and to elucidate the ceramics antimicrobial behavior. The Raman probe captured an initial metabolic response of the bacteria to the adverse chemistry of the $\mathrm{Si}_{3} \mathrm{~N}_{4}$ surface, which included peroxidation of membrane phospholipids and protein structural modifications to adjust for survivorship. However, beyond $24 \mathrm{~h}$ of exposure, the Raman signals representing DNA, lipids, proteins, and carbohydrates showed clear fingerprints of bacterial lysis. Bands related to biofilm formation completely disappeared or underwent drastically reduced intensity. Bacterial lysis was confirmed by conventional fluorescence microscopy methods. Spectroscopic experiments suggested that a pH change at the $\mathrm{Si}_{3} \mathrm{~N}_{4}$ 's surface induced variations in the membrane structure and D-alanylation of teichoic acids in its peptidoglycan layer. Concurrent stimulation of peptidoglycan hydrolase (i.e., an enzyme involved with autolysis) ultimately led to membrane degradation and cellular death. An additional finding was that modulating the $\mathrm{Si}_{3} \mathrm{~N}_{4}$ surface by increasing the population of amine groups improved the efficiency of the substrate against $S$. epidermidis, thus suggesting that optimization of the near-surface (alkaline) conditions may be a viable approach to bacterial reduction. @ 2018 Society of Photo-Optical Instrumentation Engineers (SPIE) [DOI: 10.1117/1.JBO.23.5.056002]
\end{abstract}

Keywords: silicon nitride; Staphylococcus epidermidis; bacteriostatic behavior; Raman spectroscopy.

Paper 180102R received Feb. 16, 2018; accepted for publication Apr. 9, 2018; published online May 9, 2018.

\section{Introduction}

One of the clinical research goals during the last decade has been the clarification of staphylococcal pathogenesis mechanisms as they relate to implanted biomaterials for joint prostheses, catheters, heart valves, and pacemakers. ${ }^{1}$ The pathogen which represents a common source of infections on indwelling medical devices is Staphylococcus epidermidis, a gram-positive bacterium that permanently resides on human skin and in mucosa membranes. S. epidermidis is capable of adhering to synthetic biomaterial surfaces and forming a stable biofilm leading to persistent infections. ${ }^{2,3}$ During biofilm formation, bacterial cells secrete extracellular polymeric substances that include lipids, proteins, polysaccharides, and others; these protect the bacterial colony from external attack. ${ }^{4,5}$ Accordingly, treating biofilm-

*Address all correspondence to: Giuseppe Pezzotti, E-mail: pezzotti@ kit.ac.jp related infections is extremely difficult. Actions of the immune system can be ineffective and eradication of the pathogen often requires extreme doses of antibiotics. Biofilm-encased bacteria are up to a 1000 times more resistant to bactericidal drugs than their planktonic predecessors. ${ }^{6}$ In addition, for patients with compromised immune systems, the release of bacteria from the biofilm often triggers remote secondary site infections. One possible way of preventing periprosthetic infections is to design biomaterials with physical or chemical barriers that are capable of inherently resisting bacterial surface adhesion. ${ }^{7,8}$ One candidate material with such properties is $\mathrm{Si}_{3} \mathrm{~N}_{4}$, a nonoxide ceramic whose surface can be chemically and topographically altered. ${ }^{9}$ Previous tests conducted by Bock et al. ${ }^{9}$ verified the antibacterial behavior of this bioceramic. They compared the bacteriostatic characteristics of different biomaterials used in medical 
devices against S. epidermidis and Escherichia coli (E. coli). Their results showed a pronounced reduction in bacteria adhesion and live bacteria with increased exposure to $\mathrm{Si}_{3} \mathrm{~N}_{4}$.

Raman spectroscopy on living bacteria has been employed to follow its metabolism and to understand the chemical interactions between bacterial cells and biomaterials. ${ }^{10-12}$ This in situ spectroscopic technique is useful in identifying and observing specific time-dependent biochemical changes in the composition and activity of prokaryotic cells. Neugebauer et al. ${ }^{10}$ succeeded in characterizing $S$. epidermidis with respect to its metabolic functions using different spectroscopic techniques; Samek et al. ${ }^{11}$ analyzed the formation of $S$. epidermidis biofilm by labeling characteristic Raman bands in its spectrum. The metabolism of gram-negative Porphyromonas gingivalis was also clarified in a recent paper before and after its inoculation onto various $\mathrm{Si}_{3} \mathrm{~N}_{4}$ substrates. ${ }^{12}$

In this study, the in situ metabolic activity, cellular growth, and lysis of $S$. epidermidis were examined at different time points under the chemical and physical influences of various $\mathrm{Si}_{3} \mathrm{~N}_{4}$ substrates. Comparative data were also acquired on two other popular biomaterials: polyetheretherketone (PEEK) and a titanium alloy (Ti). In situ Raman spectroscopy provided physicochemical insights into the interaction of $S$. epidermidis colonies with these various biomaterials, from which a mechanistic understanding of $\mathrm{Si}_{3} \mathrm{~N}_{4}$ 's bacteriostatic behavior was proposed.

\section{Materials and Methods}

\subsection{Investigated Biomaterials}

The $\mathrm{Si}_{3} \mathrm{~N}_{4}$ samples were produced by Amedica Corporation (Salt Lake City, Utah) using conventional ceramic fabrication techniques. ${ }^{13}$ In brief, 90 wt. $\% \mathrm{Si}_{3} \mathrm{~N}_{4}$ powder (Ube SN E-10, Ube City, Japan) was mixed with 6 wt. \% yttrium oxide $\left(\mathrm{Y}_{2} \mathrm{O}_{3}\right.$, Grade C, H. C. Starck, Munich, Germany) and 4 wt. \% aluminum oxide $\left(\mathrm{Al}_{2} \mathrm{O}_{3}, \mathrm{SA} 8\right.$-DBM, Baikowski/Malakoff, Charlotte, North Carolina) followed by comminution and spray drying. The $\mathrm{Y}_{2} \mathrm{O}_{3}$ and $\mathrm{Al}_{2} \mathrm{O}_{3}$ additives served as sintering aids. Disk samples $(\varnothing 12.7 \times 1 \mathrm{~mm})$ were dry-pressed, debinderized, and sintered in a nitrogen atmosphere at temperatures in excess of $1700^{\circ} \mathrm{C}$ and further densified by hot-isostatic pressing at $>1650^{\circ} \mathrm{C}$ under a $\mathrm{N}_{2}$ gas pressure of $>200 \mathrm{MPa}$. The resulting dense $\mathrm{Si}_{3} \mathrm{~N}_{4}$ samples consisted of a two-phase microstructureacicular $\beta-\mathrm{Si}_{3} \mathrm{~N}_{4}$ grains and a grain boundary phase of amorphous or crystalline yttrium aluminum oxynitride (i.e., SiYAION) ${ }^{14}$ The resulting disks were designated as "untreated" or "as-fabricated" $\mathrm{Si}_{3} \mathrm{~N}_{4}$. A subset of these disks was further subjected to postdensification annealing in a nitrogen atmosphere $(\sim 1.1$ bar) at $1400^{\circ} \mathrm{C}$ for $30 \mathrm{~min}$. Following this heat treatment, the surface density of amines relative to hydroxyl groups increased ${ }^{15}$ and a fraction of SiYAlON glass migrated to the sample's surfaces. Comparative testing was also performed on dimensionally identical samples of PEEK (ASTM D6262, Ketron ${ }^{\circledR}$ PEEK 1000, Quadrant EPP USA, Inc., Reading, Pennsylvania, distributed by McMaster-Carr, Santa Fe Springs, California) and a Ti-alloy (ASTM F136, Ti6Al4V-ELI, distributed by Vincent Metals, Minneapolis, Minnesota). The PEEK and Ti-alloy samples were used as negative and positive controls, respectively.

\subsection{Bacterial Culture}

S. epidermidis $\left(14990^{\circledR}\right.$ ATCC $\left.{ }^{\mathrm{TM}}\right)$ was cultured at the Kyoto Prefectural University of Medicine using a brain heart infusion
(BHI) Agar medium. The initial $1.8 \times 10^{10} \mathrm{CFU} / \mathrm{ml}$ was subsequently diluted to $1 \times 10^{8} \mathrm{CFU} / \mathrm{ml}$ using a phosphate-buffered saline solution to mimic ion blood concentrations. Then, $100 \mu \mathrm{L}$ of bacteria solution were transferred to separate Petri dishes containing the BHI agar. All samples were sterilized by UV before inoculation with the bacteria. Incubation at $37^{\circ} \mathrm{C}$ took place under aerobic conditions for three time-points: 12 , 24 , and $48 \mathrm{~h}$, respectively.

\subsection{Laser Microscopy}

The surface morphology of the studied substrates, which can affect the primary interaction between the implant body and the environment, was characterized with respect to its microscopic topography. Average roughness, $R a$, for the different surfaces was acquired using a confocal scanning laser microscope (Laser Microscope 3D \& Profile measurements, Keyence, VKx200 Series, Osaka, Japan) capable of high-resolution optical images with depth selectivity. The average roughness was calculated as the mean value over 36 images randomly acquired on each sample using $150 \times$ magnification.

\subsection{Fluorescence Microscopy and Microbial Viability Assay}

After exposure to the different material surfaces, bacterial samples were observed using a fluorescence microscope (BZ-X700; Keyence, Osaka, Japan). To facilitate their examination, the bacteria were stained with different solutions: propidium iodide (PI; Dojindo, Kumamoto, Japan), 5(6)-carboxyfluorescein diacetate (CFDA; Dojindo, Kumamoto, Japan), and 4',6-diamidino2-phenylindole (DAPI; Dojindo, Kumamoto, Japan). PI's red color highlighted dead or injured bacteria; CFDA's green color revealed living bacteria; and DAPI, which binds to DNA, verified cell nuclei locations. The staining protocol consisted of adding $1 \mu \mathrm{L}$ of DAPI, the PI solution, and $15 \mu \mathrm{L}$ of CFDA solution to the samples, and then incubating for $5 \mathrm{~min}$ at $37^{\circ} \mathrm{C}$. After removing the buffer, the cells were stained and analyzed under the fluorescence microscope. The exposure time for each image was $5 \mathrm{~s}$ under an $80-\mathrm{W}$ metal halide lamp. After exposures of 12 and $48 \mathrm{~h}$, bacterial metabolism was examined using a colorimetric assay (Microbial Viability Assay Kit-WST, Dojindo, Kumamoto, Japan). This assay employed a colorimetric indicator (WST-8), which produces a water-soluble formazan dye upon reduction in the presence of an electron mediator. The amount of the formazan dye generated is directly proportional to the number of living microorganism. Solutions were analyzed using microplate readers (EMax, Molecular Devices, Sunnyvale, California) via an optical density (OD) method for living cells. ${ }^{16}$

\subsection{In Situ Raman Spectroscopy}

Time-lapse Raman spectra were collected after exposure of cultured $S$. epidermidis to two different $\mathrm{Si}_{3} \mathrm{~N}_{4}$ samples, a Ti-alloy, and silica glass control (Silanized Slides; DAKO, Denmark). Spectra for bacteria on PEEK samples could not be obtained due to the high fluorescence emitted from the PEEK material. Spectra were collected using a confocal Raman microscope (LabRAM HR800; Horiba/Jobin-Yvon, Kyoto, Japan), which employed a single monochromator connected to an air-cooled CCD detector (Andor DV420-OE322; $1024 \times 256$ pixels). The excitation radiation was provided by a coherent helium-neon lamp emitting at $633 \mathrm{~nm}$ with a power of $\sim 10 \mathrm{~mW}$ at the sample 

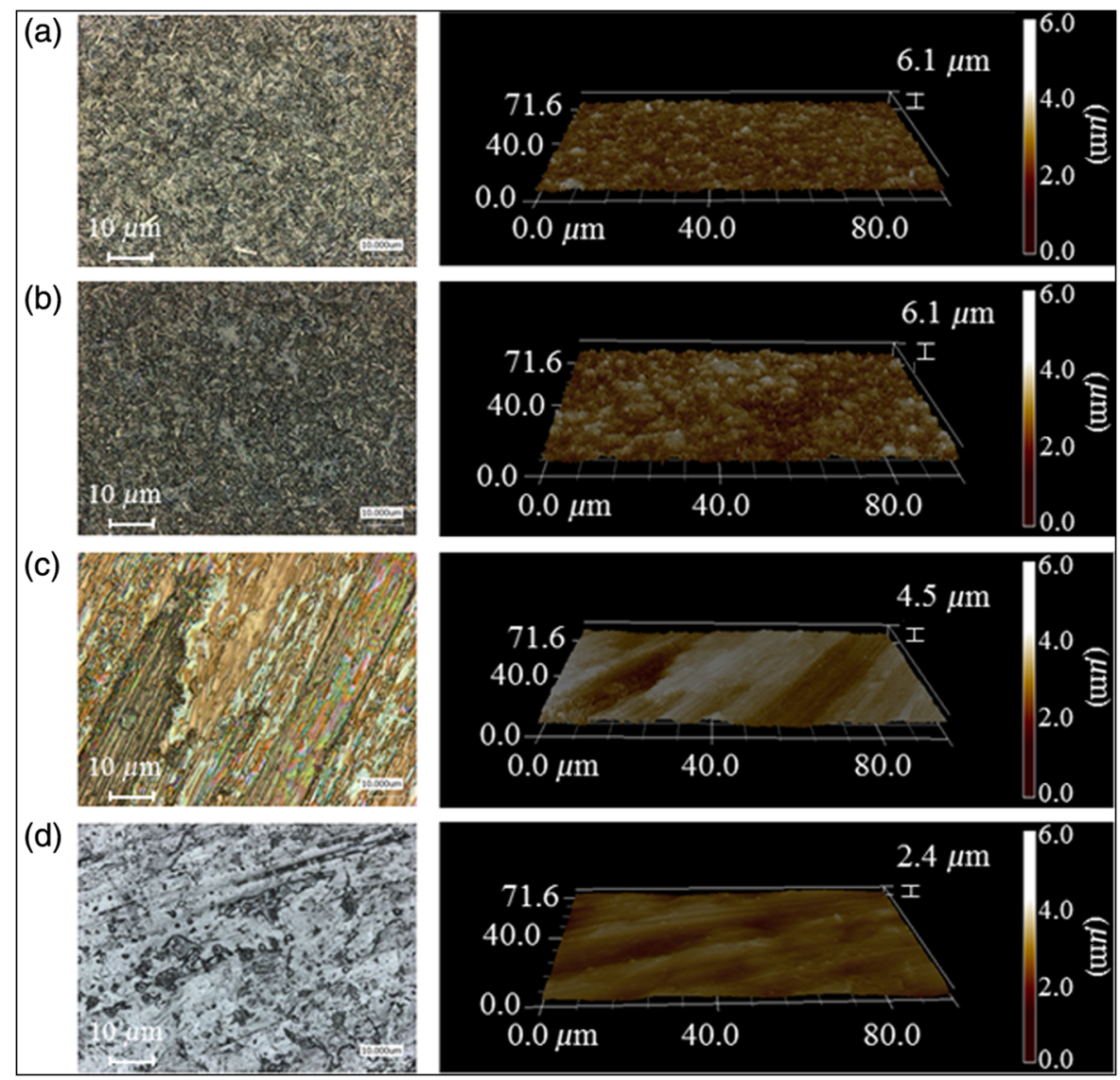

Fig. 1 Laser micrographs (left side) and relative topography plots (right side) of (a) untreated $\mathrm{Si}_{3} \mathrm{~N}_{4}$, (b) $\mathrm{N}_{2}$-annealed $\mathrm{Si}_{3} \mathrm{~N}_{4}$, (c) Ti-alloy, and (d) PEEK. Images are obtained before bacterial treatment at $150 \times$ magnification.

surface. A $600 \mathrm{gr} / \mathrm{mm}$ grating and a D.03 holographic notch filter were employed with a $100 \times$ objective lens. A $100-\mathrm{mm}$ cross slit and a 200-mm confocal pinhole were employed. The Raman spectra were acquired with an exposure time of $2 \mathrm{~s}$ in each of four different spectral ranges. Average Raman spectra for each substrate were calculated from 15 measurements at different arbitrary locations. Raman spectral acquisition and preprocessing of raw data (i.e., baseline subtraction, smoothing, normalization, and fitting) were carried out using commercially available software (LabSpec, Horiba/Jobin-Yvon, Kyoto, Japan and Origin 8.5, OriginLab Co., Northampton, Massachusetts). Baseline subtraction of all the spectra has been obtained according to the polynomial method using a polynomial function of degree 8. Fitting was performed using Gaussian/Lorentzian functions.

\subsection{Statistical Analysis}

All data were expressed as mean values \pm one standard deviation and were analyzed for their statistical significance $(p \leq 0.05)$ using the Student's $t$ test.

\section{Results}

\subsection{Topography of Substrate Surfaces}

Laser microscopy images and related three-dimensional (3-D) plots for different substrates are shown in Fig. 1. Untreated $\mathrm{Si}_{3} \mathrm{~N}_{4}$ [Fig. 1(a)] exhibited a peculiar topology with the presence of protruding acicular grains interspersed into an oxide intergranular matrix. The $\mathrm{N}_{2}$-annealed $\mathrm{Si}_{3} \mathrm{~N}_{4}$ surface [Fig. 1(b)] presented a similar acicular grain structure but also displayed increased areal fractions of the intergranular phase that was expressed from the bulk during the thermal treatment. ${ }^{15}$ Figures 1(c) and 1(d) show the surfaces of the Ti-alloy and PEEK, respectively.

The surface topology of the Ti-alloy was regular and homogeneous without the presence of secondary phases; the surface of PEEK appeared to be the smoothest of the tested materials. The average roughness, $R a$, for these samples ( $n=4$ each) is compared in Fig. 2 together with a statistical analysis of observed differences. The $\mathrm{N}_{2}$-annealed $\mathrm{Si}_{3} \mathrm{~N}_{4}$ presented the highest roughness $(0.40 \pm 0.04 \mu \mathrm{m})$ followed by the untreated $\mathrm{Si}_{3} \mathrm{~N}_{4}(0.32 \pm 0.02 \mu \mathrm{m})$. The PEEK surface possessed the lowest roughness $(0.26 \pm 0.03 \mu \mathrm{m})$, whereas the topology of the Tialloy $(0.29 \pm 0.04 \mu \mathrm{m})$ was not significantly different from untreated $\mathrm{Si}_{3} \mathrm{~N}_{4}$.

\subsection{Microbial Viability Assays and Fluorescence Microscopy}

As shown in Figs. 3(a) and 3(b), bacterial cell viability was verified at 12 and $48 \mathrm{~h}$, respectively. After $12 \mathrm{~h}$ of exposure, the $\mathrm{N}_{2}$-annealed $\mathrm{Si}_{3} \mathrm{~N}_{4}$ showed the highest OD value (3.12 \pm 0.044$)$ indicating the largest number of living bacteria among the studied materials. The Ti-alloy had the lowest $\mathrm{OD}$ value $(1.38 \pm$ $0.02)$, whereas the PEEK $(2.14 \pm 0.06)$ and untreated $\mathrm{Si}_{3} \mathrm{~N}_{4}$ 


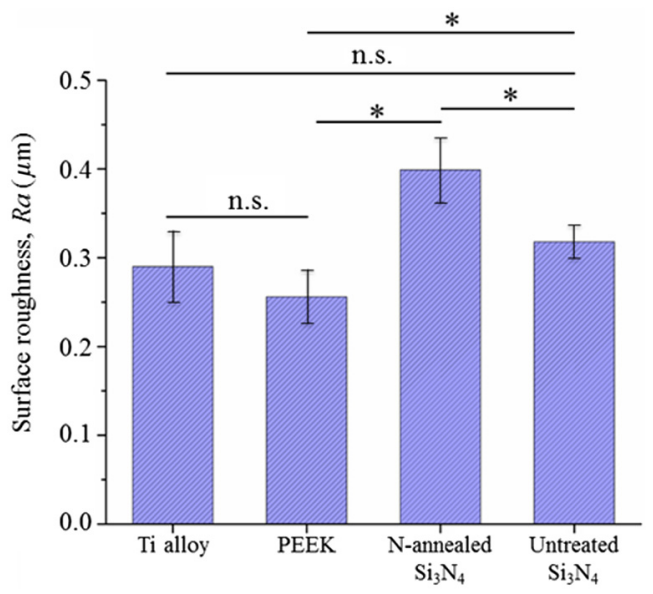

Fig. 2 Roughness parameter, $R a$, of substrate samples; $\mathrm{N}_{2}$-annealed samples were smoother than other samples (n.s. = non significant; $p<0.05$ ), whereas untreated $\mathrm{Si}_{3} \mathrm{~N}_{4}$ did not show a significant statistical difference when compared with the Ti-alloy $(p>0.05)$.

$(2.03 \pm 0.08)$ had intermediate OD values. OD values between the tested materials were significantly different $(p<0.05)$ with the exception of the PEEK and untreated $\mathrm{Si}_{3} \mathrm{~N}_{4}$. However, a noteworthy variation in bacterial growth occurred at the 48-h time-point. The highest OD value belonged to PEEK $(0.87 \pm$ 0.09 ), whereas the $\mathrm{N}_{2}$-annealed $\mathrm{Si}_{3} \mathrm{~N}_{4}$ displayed the lowest $\mathrm{OD}$ value $(0.59 \pm 0.02)$. Again, a comparison between untreated $\mathrm{Si}_{3} \mathrm{~N}_{4}(0.73 \pm 0.02)$ and the Ti-alloy $(0.69 \pm 0.04)$ resulted in a minimal statistical difference. After $48 \mathrm{~h}$, all samples were statistically different $(p<0.05)$.

Note that the OD values measured for all samples were lower at $48 \mathrm{~h}$ than at $12 \mathrm{~h}$. This was likely a consequence of the two sets of experiments being performed on independent samples, rather than representing time-series events.

At $24 \mathrm{~h}$ of exposure, fluorescence micrographs were obtained for all samples after first staining them with PI, CFDA, and DAPI markers, which colored dead bacteria (red), live bacteria (green), and nuclei (blue), respectively. Results are shown in
Fig. 4 with a constant magnification of $20 \times$ for all samples. For the silicon nitride substrates, a relatively high amount of bacteria was detected [ $c f$. DAPI blue-stained micrographs in Figs. 4(a) and 4(b)] for both the untreated and $\mathrm{N}_{2}$-annealed samples, respectively. However, PI red-stained areas associated with dead bacteria clearly indicated that significant lysis had occurred, and it was more evident on the $\mathrm{N}_{2}$-annealed material. Red stains were also detected on the Ti-alloy [Fig. 4(c)], with its surface presenting a relatively low density of bacterial cells. Micrographs on PEEK [Fig. 4(d)] confirmed no antimicrobial behavior for this material. There were no apparent dead bacteria and a high number of living cells over the entire sample's surface, indicating significant bacteria proliferation.

\subsection{Raman Spectroscopy Results}

\subsubsection{Labeling Raman emissions from control samples}

Figure 5 shows average Raman spectra collected on living $S$. epidermidis bacteria cultured on a silica glass control substrate. Three spectra are shown as a function of exposure time (12, 24, and $48 \mathrm{~h}$; as labeled in the inset) in the spectral region between 300 and $3500 \mathrm{~cm}^{-1}$. All the observed bands belonged to molecular species within $S$. epidermidis. The spectra were divided into four main regions, labeled zones I to IV, and individual bands were assigned according to their physical origin and vibrational modes in the cellular compounds ( $c f$. Fig. 5 and Tables 1-3).

In zone I, between 600 and $900 \mathrm{~cm}^{-1}$, a set of bands related to DNA and RNA dominated the Raman spectrum. In particular, the band at $720 \mathrm{~cm}^{-1}$ was attributed to adenine containing species, whereas bands at 735 and $782 \mathrm{~cm}^{-1}$ were related to a mode of adenine ring breathing in DNA and DNA phosphodiester stretching, respectively. ${ }^{17,18}$ Additional bands in this region were located at 820 and $840 \mathrm{~cm}^{-1}$, the former corresponding to out-of-plane ring breathing modes of tyrosine and the latter to the $\mathrm{C}-\mathrm{O}-\mathrm{C}$ stretching vibration of 1,4 glycosidic link in carbohydrates. ${ }^{19-21}$

Zone II at 900 to $1500 \mathrm{~cm}^{-1}$ was characterized by a series of emission bands from amides, lipids, and carbohydrates. Two

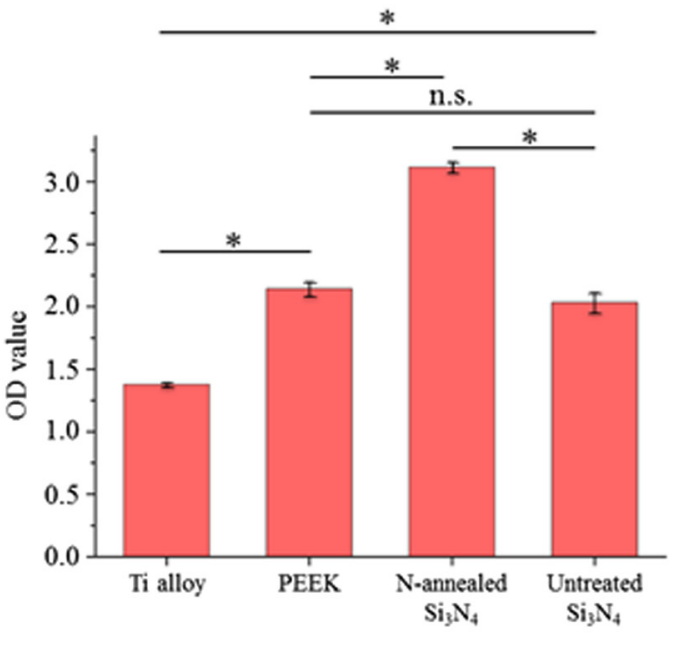

(a)

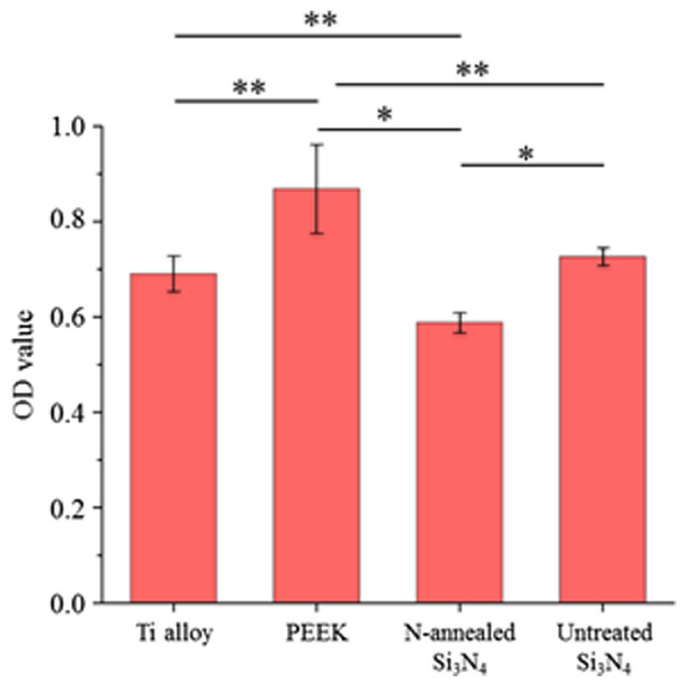

(b)

Fig. 3 WST assay diagram obtained after (a) $12 \mathrm{~h}$ and (b) $48 \mathrm{~h}$ bacterial treatment with S. epidermidis. After $48 \mathrm{~h}$, all samples showed statistical differences among each other $(p>0.05)$. 

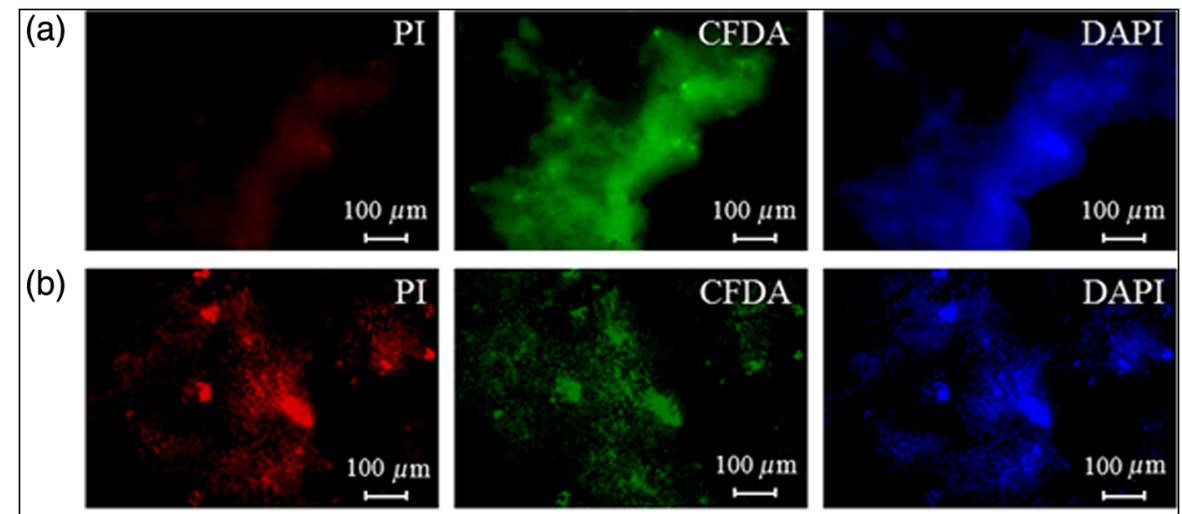

(c)
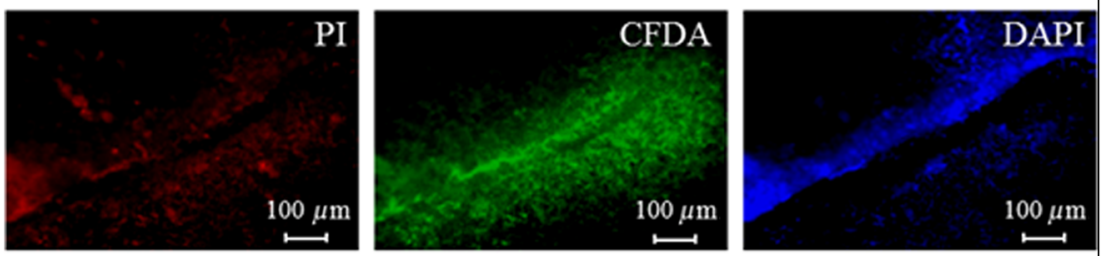

(d)
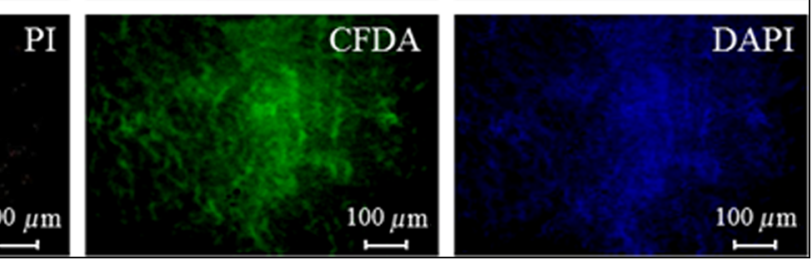

Fig. 4 Fluorescence micrograph after PI, CFDA, and DAPI staining of $S$. epidermidis exposed for $24 \mathrm{~h}$ to: (a) untreated $\mathrm{Si}_{3} \mathrm{~N}_{4}$, (b) $\mathrm{N}_{2}$-annealed $\mathrm{Si}_{3} \mathrm{~N}_{4}$, (c) Ti-alloy, and (d) PEEK. Live and dead cells were labeled with green and red stains, respectively, whereas nuclei displayed in blue color. Images were obtained at a $20 \times$ magnification.

main bands in this region, at 1092 and $1125 \mathrm{~cm}^{-1}$, are related to $\mathrm{C}-\mathrm{O}-\mathrm{C}$ antisymmetric stretching in aliphatic esters and glycosidic link of carbohydrates, and proteins, and lipids, respectively. ${ }^{22}$ Additional bands at 1253 and $1313 \mathrm{~cm}^{-1}$ are related

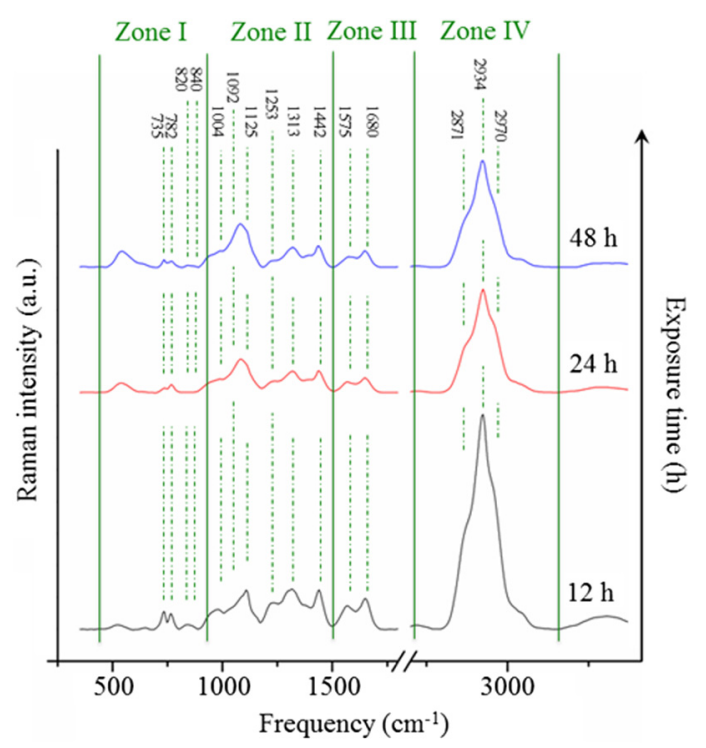

Fig. 5 Raman spectra of $S$. epidermidis ATCC 14990 in the 350 to $3500 \mathrm{~cm}^{-1}$ range collected after different exposure times to a silica glass surface used as a control sample for bacteria metabolic evolution. Spectra were divided into four distinct zones (labeled zones I to IV), while the main band frequencies were labeled according to Tables 1-3. to $\mathrm{C}-\mathrm{N}$ stretching in amide III and twisting of saturated $\mathrm{CH}_{2}$ moieties in membrane lipids, respectively. ${ }^{23,24}$ Another prominent band at $1442 \mathrm{~cm}^{-1}$ corresponds to bending of saturated $\mathrm{CH}_{2}$ in polysaccharides and membrane lipids. ${ }^{24,25}$

Zone III between 1500 and $1850 \mathrm{~cm}^{-1}$ contained one $\alpha$-helix-related band $\left(\mathrm{C}=\mathrm{O}\right.$ stretch) at $1600 \mathrm{~cm}^{-1},{ }^{18}$ but it was dominated by the $\beta$-sheet-related $\mathrm{C}=\mathrm{O}$ stretching emission of amide I at $1680 \mathrm{~cm}^{-1}{ }^{26}$

Zone IV between 2800 and $3100 \mathrm{~cm}^{-1}$ contained three main bands at $2880 \mathrm{~cm}^{-1}$ (symmetric stretching of $\mathrm{CH}_{3}$ in lipids and fatty $\operatorname{acids}^{27}$ ), $2934 \mathrm{~cm}^{-1}$ (symmetric and antisymmetric C-H stretching of $\mathrm{CH}_{2}$ and $\mathrm{CH}_{3}$ in lipids, proteins, and carbohydrates $^{28}$ ), and $2970 \mathrm{~cm}^{-1}$ (assigned to $\mathrm{CH}_{3}$ symmetric stretching in lipids and fatty acids ${ }^{29}$ ).

Looking at the time-lapse spectra collected on the control substrate revealed a slight intensity decrease of the triplet at 2881, 2934, and $2970 \mathrm{~cm}^{-1}$ and of the amide I band at $1670 \mathrm{~cm}^{-1}$ at 24-h exposure as compared with $12 \mathrm{~h}$. However, the spectrum at $48 \mathrm{~h}$ did not show significant variations as compared with $24 \mathrm{~h}$ or any significant decreases in band intensities. Rather, DNA bands of phosphodioxy groups and adenine at 1092 and $729 \mathrm{~cm}^{-1}$ experienced higher intensities after $48 \mathrm{~h}$ than after $24 \mathrm{~h}$. Another noted difference was the amide I band at $1680 \mathrm{~cm}^{-1}$. It was slightly more intense at $48 \mathrm{~h}$ compared with $24 \mathrm{~h}$. A similar trend was observed for protein and carbohydrate bands at 836 and $858 \mathrm{~cm}^{-1}$; these were completely absent after $24 \mathrm{~h}$ but were clearly visible after $48 \mathrm{~h}$. The evolution of these bands as a function of time on the silica substrate was utilized as a standard for the metabolic activity of $S$. epidermidis. It was used to establish meaningful criteria for judging 
Table 1 Band labeling, assignment, and related references in spectral zone I.

\begin{tabular}{|c|c|c|c|}
\hline Band & Assignment & $\begin{array}{l}\text { Frequency } \\
\qquad\left(\mathrm{cm}^{-1}\right)\end{array}$ & Reference \\
\hline 1 & Skeletal vibrations in tyrosine & 638 & 17,18 \\
\hline 2 & Ring vibrations in poly-deoxyadenosine & 650 & 14,15 \\
\hline 3 & Ring breathing in guanine (DNA) & 670 & 14,15 \\
\hline 4 & Phosphatidylserine & 720 & 14 \\
\hline 5 & Ring breathing adenine (DNA) & 735 & 15 \\
\hline 6 & Ring breathing in tryptophan (DNA) & 760 & 17,18 \\
\hline 7 & Phosphodiester stretching & 782 & 15 \\
\hline 8 & Out-of-plane ring breathing in DNA & 820 & 17,18 \\
\hline 9 & $\begin{array}{l}\text { COC } 1,4 \text { glycosidic link in } \\
\text { carbohydrates }\end{array}$ & 840 & 16 \\
\hline 10 & Ring breathing in trypsin (DNA) & 850 & 14 \\
\hline
\end{tabular}

Table 2 Band labeling, assignment, and related references in spectral zone II.

\begin{tabular}{|c|c|c|c|}
\hline Band & Assignment & $\begin{array}{l}\text { Frequency } \\
\left(\mathrm{cm}^{-1}\right)\end{array}$ & Reference \\
\hline 11 & $\begin{array}{l}\mathrm{C}-\mathrm{O}-\mathrm{C} \text { glycosidic linkage of } \\
\text { carbohydrates }\end{array}$ & 937 & 19 \\
\hline 12 & $\mathrm{C}-\mathrm{C}$ stretching in $\beta$-sheet & 976 & 17,18 \\
\hline 13 & Ring breathing in phenylalanine & 1004 & 17,18 \\
\hline 14 & $\begin{array}{l}\text { C-C gauche stretching in membrane } \\
\text { lipids }\end{array}$ & 1092 & 19 \\
\hline 15 & $\begin{array}{l}\mathrm{C}-\mathrm{C} \text { trans stretching in membrane } \\
\text { lipids }\end{array}$ & 1125 & 19 \\
\hline 16 & $\mathrm{C}-\mathrm{N}$ stretching amide III in $\beta$-sheet & 1253 & 20 \\
\hline 17 & $\begin{array}{l}\text { Twisting of saturated } \mathrm{CH}_{2} \text { in membrane } \\
\text { lipids }\end{array}$ & 1313 & 21 \\
\hline 18 & Symmetric stretching of O-C-O in $\mathrm{COO}^{-}$ & 1400 & 22 \\
\hline 19 & $\begin{array}{l}\text { Bending of saturated } \mathrm{CH}_{2} \text { in membrane } \\
\text { lipids }\end{array}$ & 1442 & 21 \\
\hline
\end{tabular}

changes in the bacteria's metabolism upon its exposure to the test samples. It should be noted that bands related to proteins and carbohydrates actually change with the formation of a biofilm, whereas DNA-related bands are barometers of bacterial cell proliferation and well-being.

\subsubsection{Raman emissions from $S$. epidermidis on different substrates}

Normalized Raman spectra of the bacteria as a function of exposure time on the different substrates in zone I are shown in
Table 3 Band labeling, assignment, and related references in spectral zones III and IV.

\begin{tabular}{llcc} 
Band & \multicolumn{1}{c}{ Assignment } & $\begin{array}{c}\text { Frequency } \\
\left(\mathrm{cm}^{-1}\right)\end{array}$ & Reference \\
\hline 20 & $\begin{array}{l}\mathrm{C}=\text { O stretching amide I } \\
(\alpha \text {-helix })\end{array}$ & 1600 & 15 \\
21 & $\begin{array}{l}\mathrm{C}=\text { O stretching amide I } \\
(\text { degraded structure })\end{array}$ & 1630 & 27 \\
22 & $\begin{array}{l}\mathrm{C}=\text { O stretching amide I } \\
(\beta \text {-sheet })\end{array}$ & 1680 & 23 \\
\hline
\end{tabular}

Figs. 6(a)-6(c) for 12, 24, and $48 \mathrm{~h}$, respectively. As shown in Table $1,{ }^{17,18,19-21} 10$ distinct bands were found and a number of features became visible in their time dependencies. In comparison with the control sample, the emission at $720 \mathrm{~cm}^{-1}$ (labeled as band 4 and related to phosphatidylserine) tended to disappear for both untreated and $\mathrm{N}_{2}$-annealed $\mathrm{Si}_{3} \mathrm{~N}_{4}$. In contrast, this band underwent a decrease in intensity at $>24 \mathrm{~h}$ for bacteria exposed to the Ti-alloy. In the main triplet of bands 5 to 7 , only the phosphodiester band 7 completely disappeared with elapsed time for both $\mathrm{Si}_{3} \mathrm{~N}_{4}$ substrates, whereas the DNArelated band 6 increased in relative intensity for both $\mathrm{Si}_{3} \mathrm{~N}_{4}$ samples. Band 7 persisted up to $24 \mathrm{~h}$ with a relatively strong intensity for the Ti-alloy substrate. Band 8 tended to disappear upon exposure of the bacteria to untreated $\mathrm{Si}_{3} \mathrm{~N}_{4}$, whereas it showed an increase at $24 \mathrm{~h}$ and then a reduction at $48 \mathrm{~h}$ in the case of $\mathrm{N}_{2}$-annealed $\mathrm{Si}_{3} \mathrm{~N}_{4}$. The trend found for band 8 in bacteria exposed to the Ti-alloy substrate was similar to that observed for $\mathrm{N}_{2}$-annealed substrate. Band 10 (ring breathing in trypsin) was quite strong for bacteria exposed to both types of $\mathrm{Si}_{3} \mathrm{~N}_{4}$ substrates, whereas it almost disappeared after $48 \mathrm{~h}$ on the Ti-alloy.

Spectral emissions in zone II [Figs. 7(a)-7(c) for 12, 24, and $48 \mathrm{~h}$ exposures, respectively] are shown in Table $2 .^{17-21}$

They included nine bands labeled as bands 11 to 19 . In this zone, a clear difference was noted in the trend of the phenylalanine band 13 at $\sim 1004 \mathrm{~cm}^{-1}$ for the glass control, the two $\mathrm{Si}_{3} \mathrm{~N}_{4}$ materials, and Ti-alloy. Although in the case of glass control, this band maintained a moderate relative intensity with elapsing exposure in comparison with neighboring bands, its intensity was quite pronounced for both of the $\mathrm{Si}_{3} \mathrm{~N}_{4}$ substrates and almost null for the Ti-alloy. Bands 17 to 19 , which are contributed by membrane lipids, showed an abnormal increase in their relative intensities for $S$. epidermidis at intermediate exposures to the $\mathrm{N}_{2}$-annealed substrate. A similar trend, although less pronounced, was observed for untreated $\mathrm{Si}_{3} \mathrm{~N}_{4}$ and Ti-alloy. The two bands sensitive to lipid conformation, namely bands 14 and 15 , showed a clear inverse trend in their relative intensity upon exposure to untreated $\mathrm{Si}_{3} \mathrm{~N}_{4}$ and the Ti-alloy as compared with the glass control. This change consisted of a significant increase in the latter band, which can be interpreted as a lipid population with a trans versus a gauche configuration.

Amide I dominated zone III [1500 to $1750 \mathrm{~cm}^{-1}$; Figs. 7(a)$7(\mathrm{c})$; Table $\left.{ }^{18,25,29,30}\right]$ with its main feature being band $21(\mathrm{C}=\mathrm{O}$ stretching emission at $\left.1680 \mathrm{~cm}^{-1}\right)$. This band followed the same trend observed for the lipid-related bands 17 to 19 in zone II, namely a significant enhancement at intermediate exposure times for both $\mathrm{Si}_{3} \mathrm{~N}_{4}$-based substrates, but it was more pronounced for 


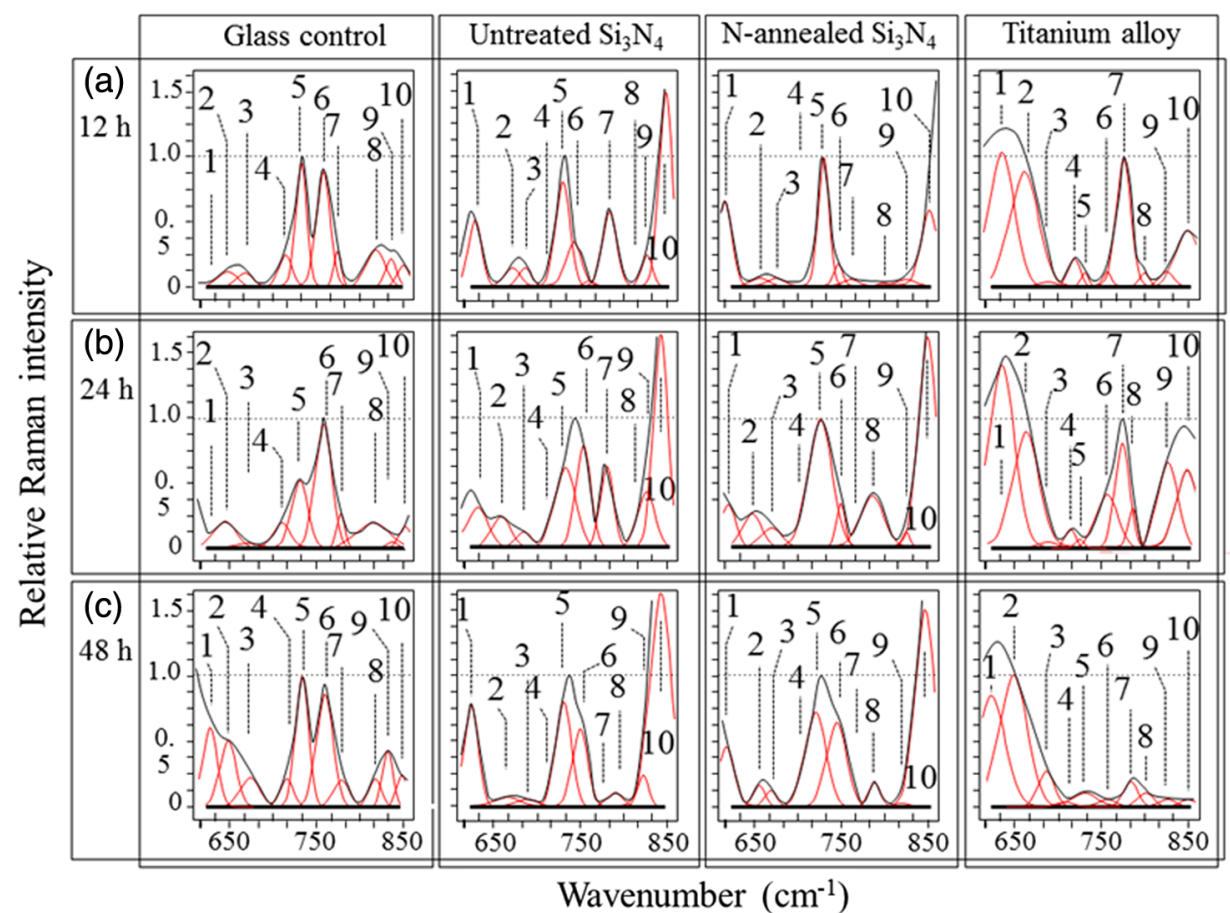

Fig. 6 Normalized and deconvoluted Raman spectra in spectral zone I from S. epidermidis exposed to different substrates (cf. labels in the inset to each column) for (a) $12 \mathrm{~h}$, (b) $24 \mathrm{~h}$, and (c) $48 \mathrm{~h}$.

the $\mathrm{N}_{2}$-annealed material. An enhancement in the relative intensity of band 21 was also observed for the Ti-alloy as compared with glass control. However, no significant differences were noted as a function of exposure time up to $48 \mathrm{~h}$.

\section{Discussion}

Mechanisms of bacterial adhesion onto and interaction with biomaterial surfaces are complex and depend on many factors, such as morphological and chemical features of the surfaces. Surface topography plays a fundamental role in bacteria/substrate interaction affecting both adhesion and biofilm formation. In general, rough surfaces promote adhesion and colonization. ${ }^{31}$ For example, Yoda et al. ${ }^{32}$ tested the bacteriostatic behavior of different substrates with controlled surface roughness with respect to S. epidermidis. They showed that adhesion and proliferation were greatly favored on rougher materials. However, nanorough

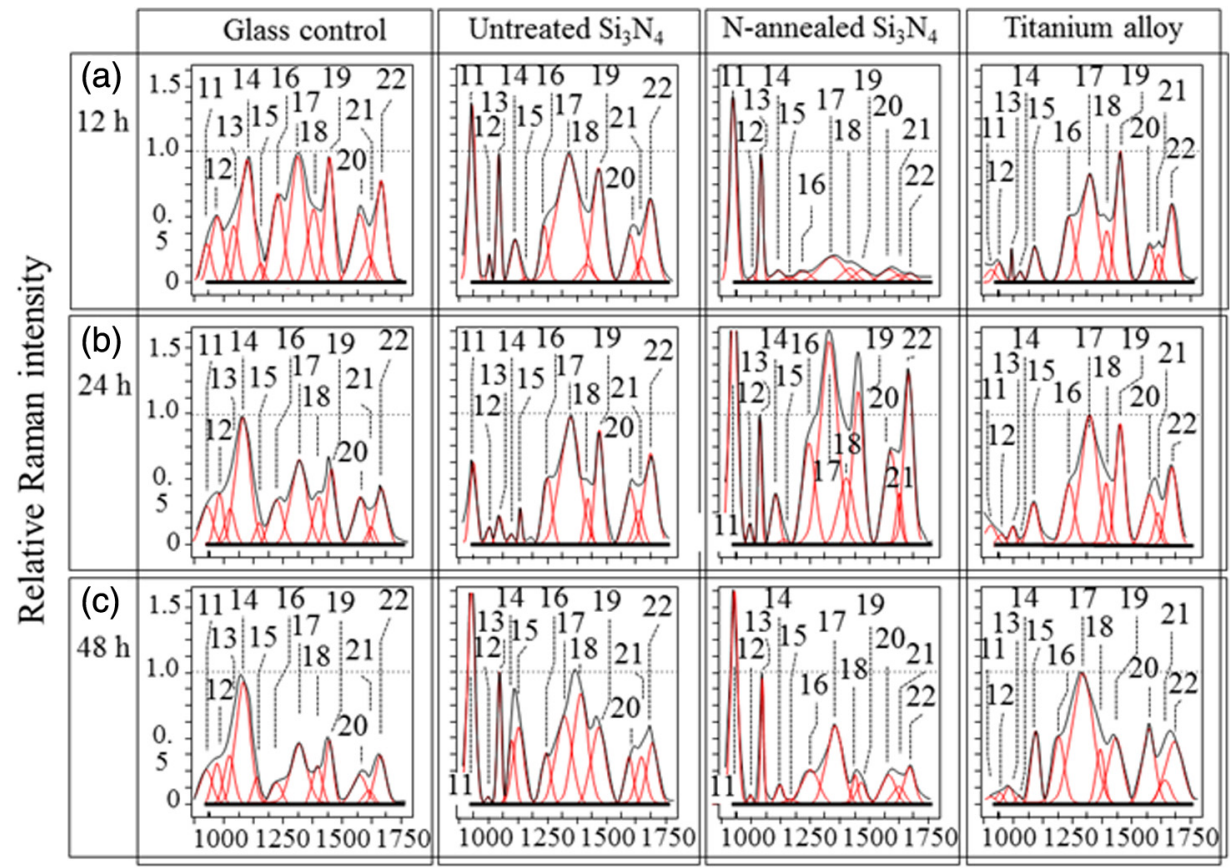

Wavenumber $\left(\mathrm{cm}^{-1}\right)$

Fig. 7 Normalized and deconvoluted Raman spectra in spectral zones II and III from S. epidermidis exposed to different substrates (cf. labels in the inset to each column) for (a) $12 \mathrm{~h}$, (b) $24 \mathrm{~h}$, and (c) $48 \mathrm{~h}$. 

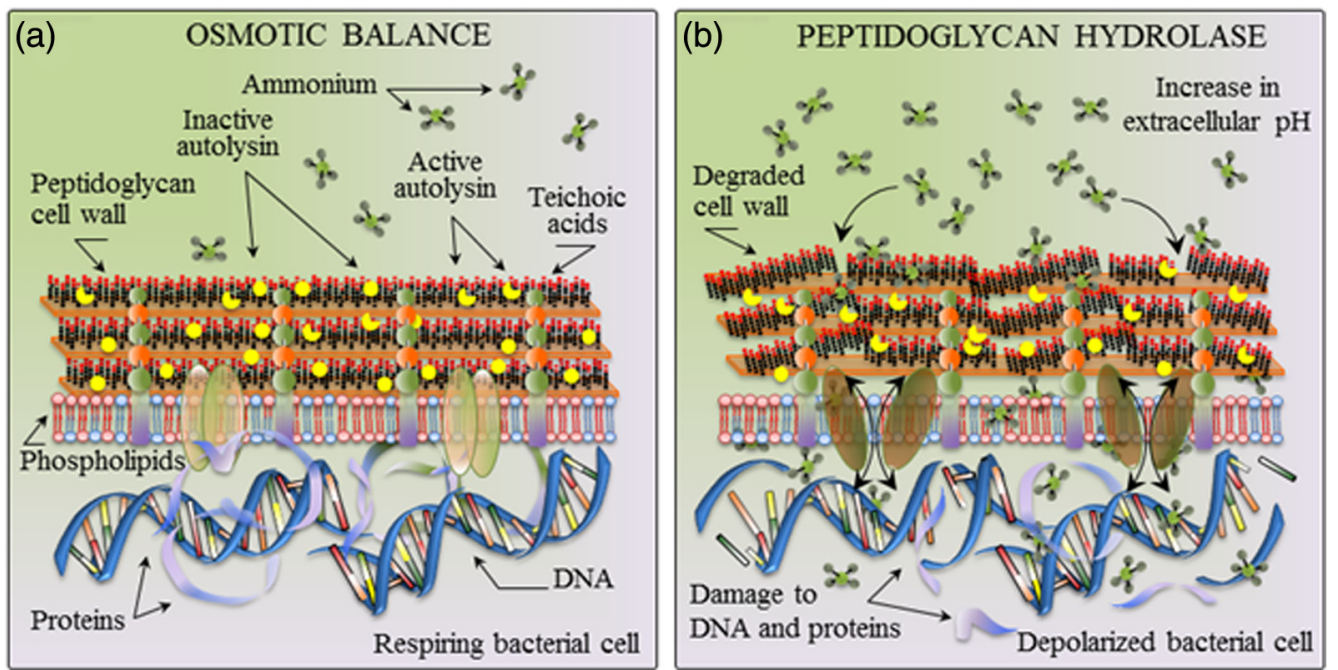

Fig. 8 (a) Schematic model of S. epidermidis bacterial membrane in osmotic equilibrium and (b) in depolarized status after being affected by polyglycan hydrolase.

surfaces have an opposite effect. Inspired by nature, the nanostructured surfaces of cicada wings ${ }^{33}$ have led to the development of engineered antimicrobial features on various biomaterials including titanium, polyurethane, and PEEK. ${ }^{34-37}$ Additionally, as demonstrated by two independent studies, the nanofeatures of untreated $\mathrm{Si}_{3} \mathrm{~N}_{4}$ proved to be more resistant to bacterial adhesion and biofilm formation than chemically identical substrates that were either machined or polished. ${ }^{38,39}$

In this study, the $\mathrm{N}_{2}$-annealed $\mathrm{Si}_{3} \mathrm{~N}_{4}$ presented the highest $R a$ value among the tested materials ( $c f$. Fig. 2). It also showed the highest amount of living cells after $12 \mathrm{~h}$ according to microbial viability tests [cf. Fig. 3(a)]. Conversely, the PEEK substrate had the smoothest surface among the tested substrates, but the amount of living bacteria on its surface after $12 \mathrm{~h}$ was comparable with the untreated $\mathrm{Si}_{3} \mathrm{~N}_{4}$ and Ti-alloy despite the fact that these latter materials experienced substantially higher $R a$ values. The situation after $48 \mathrm{~h}$ was found completely reversed with the $\mathrm{N}_{2}$-annealed $\mathrm{Si}_{3} \mathrm{~N}_{4}$ possessing the lowest quantity and the PEEK having the highest amount of living bacteria among the tested samples. These data suggest that the bacteriostatic behavior of the tested surfaces cannot simply be interpreted using surface roughness data alone. Surface chemistry needs to be taken into consideration as well. The chemical reactions at the surface of $\mathrm{Si}_{3} \mathrm{~N}_{4}$ were discussed in a previous study. ${ }^{12}$ They suggested the existence of a diffusion-limited thermodynamic driving force to convert silicon nitride into silicic acid $\left(\mathrm{Si}(\mathrm{OH})_{4}\right)$ and ammonia $\left(\mathrm{NH}_{3}\right)$. Release of $\mathrm{NH}_{3}$ from the ceramic surface was experimentally demonstrated by a significant increase in local $\mathrm{pH}$ (i.e., from $\sim 5.5$ to $\sim 8.5$ ). ${ }^{12}$ As indicated by prior research, highly alkaline environments may delay or prevent bacterial adhesion and biofilm formation. For instance, Hamadi et al. ${ }^{40}$ investigated the adhesion of Staphylococcus aureus to glass at different $\mathrm{pH}$ values and observed that bacteria strongly adhered in the $\mathrm{pH}$ range 4 to 6 , whereas adhesion was weak under both highly acidic $(\mathrm{pH} \approx 2$ to 3 ) and alkaline conditions $(\mathrm{pH}>7)$.

Raman spectroscopy provided further insight into the bacteria's metabolism by showing the time-dependent variations of its molecular structure after contact with the different substrates. A significant reduction in the intensity of its DNA-related bands in spectral zone I (e.g., bands 2, 3, 7, and 8) after $48 \mathrm{~h}$ of exposure to both types of $\mathrm{Si}_{3} \mathrm{~N}_{4}$ and the Ti-alloy substrates was an important indicator of its metabolic degradation. Escoriza et al. ${ }^{41}$ studied the time-lapse Raman response of bacteria during their proliferation and found that bands related to nucleic bases typically showed high intensities at the beginning of bacterial growth, but their intensities slowly decreased with time. In the current experiments, a similar initial trend coupled with an abrupt decrease at $48 \mathrm{~h}$ was observed. This sudden decrease strongly suggests that both $\mathrm{Si}_{3} \mathrm{~N}_{4}$ materials and the Ti-alloy possess inherent antibacterial mechanisms.

Alterations of phospholipid-related and protein-related bands were also observed, which indicated major irreversible modifications to the bacteria's membrane and protein structures. The spectral bands at $1125 \mathrm{~cm}^{-1}$ (band 15) and $1442 \mathrm{~cm}^{-1}$ (band 19) monitor the polysaccharides for intercellular adhesion and biofilm formation. ${ }^{42,43}$ These bands initially increased but then conspicuously disappeared after exposure to $\mathrm{N}_{2}$-annealed $\mathrm{Si}_{3} \mathrm{~N}_{4}$ for $48 \mathrm{~h}$. This trend can be interpreted as disruption of the biofilm after its initial formation at intermediate times. An important marker for proteins is band 13 at $1004 \mathrm{~cm}^{-1}$ related to vibrational modes in phenylalanine. However, this band tended to disappear only for bacteria exposed to the Ti-alloy. The strong band 17 (at $1313 \mathrm{~cm}^{-1}$ ) reflects twisting vibrations of saturated $\mathrm{CH}_{2}$ bonds in membrane lipids. When comparing the relative intensity of this band to that of phenylalanine (band 13), a significant enhancement was noticed after $24 \mathrm{~h}$ of exposure to both types of $\mathrm{Si}_{3} \mathrm{~N}_{4}$ surfaces, followed by a clear intensity reduction after $48 \mathrm{~h}$. The intensity enhancement of bands 17 was interpreted as acidification of the membrane lipids. ${ }^{24}$ However, bacteria have an ability to control the biophysical properties of the phospholipids in their membranes in the presence of an external physiological stress ${ }^{44}$ and this was observed via Raman spectroscopic monitoring in the current experiments. Following the work of Nostro et al., ${ }^{45}$ the bacterial behavior observed on the $\mathrm{Si}_{3} \mathrm{~N}_{4}$ substrates was interpreted as a reaction to the increase in local $\mathrm{pH}$. This reaction reduced the bacteria's initial adhesion capability and subsequently led to the impairment of biofilm maturation. An alkaline $\mathrm{pH}$ directly influences bacterial attachment because it affects the degree of D-alanylation of lipoteichoic acid and wall teichoic acid, which are the most abundant polyanions in cytoplasmic membrane lipids and are linked to peptidoglycan. Another important aspect of 
the change in $\mathrm{pH}$ is its impact on enzymes related to autolysis of prokaryotic cells. A pH change favors activation of autolysin leading to peptidoglycan hydrolases, which strongly alters peptidoglycan, turn over. When hydrolase is activated, peptidoglycans are degraded and the osmotic balance of the bacterial cell is lost with the cell turning from a respiring to a depolarized status. Ammonium moieties released from the $\mathrm{Si}_{3} \mathrm{~N}_{4}$ surface ${ }^{12}$ then become free to flow into the cytoplasmic environment because the structural integrity of the cell wall is compromised. This process ultimately results in cell lysis. ${ }^{46}$ Figure 8 shows a schematic model of $S$. epidermidis exposed to a silicon nitride surface with a time-dependent increase in local $\mathrm{pH}$. A process of uncontrolled autolysis is envisaged, which modifies the peptidoglycan wall structure and increases the susceptibility of the membranes to molecular moieties liberated by the substrate, thereby destabilizing the cell.

\section{Conclusion}

To clarify the origin of $\mathrm{Si}_{3} \mathrm{~N}_{4}$ 's bacteriostatic behavior, changes within gram-positive $S$. epidermidis were studied after its exposure to substrates consisting of two $\mathrm{Si}_{3} \mathrm{~N}_{4}$ variants, a Ti-alloy and a glass control for time-points up to $48 \mathrm{~h}$. Previously reported results were confirmed using microbial viability assays and fluorescence microscope analyses. Then, in situ Raman spectroscopy was employed to monitor the metabolic variations of the bacteria at different exposure times. These variations were interpreted based on the vibrational responses of their biological DNA. The Raman spectra showed a decrease in the band intensities related to biofilm formation and DNA after $48 \mathrm{~h}$ suggesting the initiation of lysis. The Raman data agreed with the results derived from the biological tests. Based on these observations and in comparison with previously published literature, the metabolic changes in $S$. epidermidis were attributed to a $\mathrm{pH}$ drift toward alkaline values on the $\mathrm{Si}_{3} \mathrm{~N}_{4}$ surfaces. This drift modified the behavior of enzymes and cellular compounds, limiting its adhesion and increasing the permeability of the cell walls. In conclusion, this study demonstrated that the surface chemistry of $\mathrm{Si}_{3} \mathrm{~N}_{4}$ may be useful in inhibiting periprosthetic infections by hindering biofilm formation and bacterial proliferation.

\section{Disclosures}

Competing financial interests: Giuseppe Pezzotti is a consultant to Amedica Corporation, and Bryan McEntire works at Amedica Corporation.

\section{References}

1. O. Samek et al., "Raman spectroscopy for rapid discrimination of Staphylococcus epidermidis clones related to medical device-associated infections," Laser Phys. 5, 465-470 (2008).

2. D. Mack et al., "Biofilm formation in medical device-related infection," Int. J. Artif. Organs 29, 343-359 (2006).

3. L. G. Harris and R. G. Richards, "Staphylococci and implant surfaces: a review," Injury 37(Suppl. 1), S3-S14 (2006).

4. I. W. Sutherland, "Biofilm exopolysaccharides: a strong and sticky framework," Microbiology 147, 3-9 (2001).

5. C. Vuong and M. Otto, "Staphylococcus epidermidis infections," Microbes. Infect. 4, 481-489 (2002).

6. P. S. Stewart and J. W. Costerton, "Antibiotic resistance of bacteria in biofilms," Lancet 358, 135-138 (2001).

7. K. Vasilec, J. Cook, and H. J. Griesser, "Antibacterial surface for biomedical devices," Expert Rev. Med. Devices 6, 553-567 (2009).
8. D. Campoccia, L. Montanaro, and C. R. Arciola, "A review of the biomaterials technologies for the infection-resistant surfaces," Biomaterials 34, 8533-8554 (2013).

9. M. R. Bock et al., "Bacteriostatic behavior of surface modulated silicon nitride in comparison to polyetheretherketone and titanium," J. Biomed. Mater. Res. Part A 105, 1521-1534 (2017).

10. U. Neugebauer et al., "Towards a detailed understanding of bacterial metabolism-spectroscopic characterization of staphylococcus epidermidis," Chem. Phys. Chem. 8, 124-137 (2007).

11. O. Samek, J. F. M. Al-Marashi, and H. H. Telle, "The potential of Raman spectroscopy for the identification of biofilm formation by Staphylococcus Epidermidis," Laser Phys. Lett. 7, 378-383 (2010).

12. G. Pezzotti et al., "Silicon nitride bioceramics induce chemically driven lysis in Porphyromonas Gingivalis," Langmuir 32, 3024-3035 (2016).

13. B. J. McEntire et al., "Processing and characterization of silicon nitride bioceramics," Bioceram. Dev. Appl. 6, 1000093 (2016).

14. G. Roebben et al., "Quantitative determination of the volume fraction of intergranular amorphous phase in sintered silicon nitride," Mater. Sci. Eng. A 370, 453-458 (2004).

15. R. M. Bock et al., "Surface modulation of silicon nitride ceramics for orthopaedic applications," Acta Biomater. 26, 318-330 (2015).

16. S. E. McBirney et al., "Wavelength-normalized spectroscopic analysis of Staphylococcus aureus and Pseudomonas aeruginosa growth rates," Biomed. Opt. Express 7, 4034-42 (2016).

17. G. I. Dovbeshko et al., "Surface enhanced IR absorption of nucleic acids from tumor cells: FTIR reflectance study," Biopolymer 67, 470-486 (2002).

18. A. C. Williams and H. G. M. Edwards, "Fourier transform Raman spectroscopy of bacterial cell walls," J. Raman Spectrosc. 25, 673-677 (1994).

19. A. C. Sekhar Talari et al., "Raman spectroscopy of biological tissues," Appl. Spectrosc. Rev. 50, 46-111 (2015).

20. I. Notingher and L. L. Hench, "Raman microspectroscopy: a noninvasive tool for studies of individual living cells in vitro," Expert Rev. Med. Dev. 3, 215-234 (2006).

21. Z. Movasaghi, S. Rehman, and I. U. Rehman, "Raman spectroscopy of biological tissue," Appl. Spectrosc. Rev. 42, 493-541 (2007).

22. R. M. Jarvis, A. Brooker, and R. Goodacre, "Surface-enhanced Raman spectroscopy for bacterial discrimination utilizing a scanning electron microscope with a Raman spectroscopy interface," Anal. Chem. 76, 5198-5202 (2004).

23. S. Cai and B. R. Singh, "Identification of beta-turn and randomcoil amide III infrared bands for secondary structure estimation of proteins," Biophys. Chem. 80, 7-20 (1999).

24. H. Wu et al., "In vivo lipidomics using single-cell Raman spectroscopy," Proc. Natl. Acad. Sci. U.S.A. 108, 3809-3814 (2011).

25. B. Beltran et al., "The effect of nitric oxide on cell respiration: a key to understanding its role in cell survival or death," Proc. Natl. Acad. Sci. U. S.A. 97, 14602-14607 (2000).

26. R. K. Poole and M. N. Hughes, "New functions for the ancient globin family: bacterial responses to nitric oxide and nitrosative stress," Mol. Microbiol. 36, 775-783 (2000).

27. S. Kolijenovic et al., "Detection of meningioma in dura mater by Raman spectroscopy," Anal. Chem. 77, 7958-7965 (2005).

28. N. J. Kline and P. J. Treado, "Raman chemical imaging of breast tissue," J. Raman Spectrosc. 28, 119-124 (1997).

29. G. Shetty et al., "Raman spectroscopy: evaluation of biochemical changes in carcinogenesis of oesophagus," Br. J. Cancer 94, 14601464 (2006).

30. D. A. Wink and J. B. Mitchell, "Chemical biology of nitric oxide: insights into regulatory, cytotoxic, and cytoprotective mechanisms of nitric oxide," Free Radical Biol. Med. 25, 434-456 (1998).

31. O. Öztürk, M. Sudagidan, and U. Türkan, "Biofilm formation by Staphylococcus epidermidis on nitrogen ion implanted CoCrMo alloy material," J. Biomed. Mater. Res. 81A, 663-668 (2007).

32. I. Yoda et al., "Effect of surface roughness of biomaterials on Staphylococcus Epidermidis adhesion," BMC Microbiol. 14, 234 (2014).

33. E. P. Ivanova et al., "Natural bactericidal surfaces: mechanical rupture of pseudomonas Aeruginosa cells by cicada wings," Small 8, 2489-2494 (2012).

34. S. D. Puckett et al., "The relationship between the nanostructure of titanium surfaces and bacterial attachment," Biomaterials 31, 706-713 (2010). 
35. A. V. Singh et al., "Quantitative characterization of the influence of the nanoscale morphology of nanostructured surfaces on bacterial adhesion and biofilm formation," PLoS One 6, e25029 (2011).

36. L.-C. Xu and C. A. Siedlecki, "Submicron-textured biomaterial surface reduces Staphylococcal bacterial adhesion and biofilm formation," Acta Biomater. 8, 72-81 (2012).

37. M. Wang, G. Bhardwaj, and T. Webster, "Antibacterial properties of PEKK for orthopedic applications," Int. J. Nanomed. 12, 6471-6476 (2017).

38. M. Ishikawa et al., "Surface topography of silicon nitride affects antimicrobial and Osseointegrative properties of tibial implants in a murine model," J. Biomed. Mater. Res. A 105, 3413-3421 (2017).

39. D. J. Gorth et al., "Decreased bacteria activity on $\mathrm{Si}_{3} \mathrm{~N}_{4}$ surfaces compared with PEEK or titanium," Int. J. Nanomed. 7, 4829-4840 (2012).

40. F. Hamadi et al., "Effect of $\mathrm{pH}$ on distribution and adhesion of Staphylococcus Aureus to glass," J. Adhes. Sci. Technol. 19, 73-85 (2005).

41. M. F. Escoriza et al., "Raman spectroscopic discrimination of cell response to chemical and physical inactivation," Appl. Spectrosc. 61, 812-823 (2007).

42. M. Harz et al., "Micro-Raman spectroscopic identification of bacterial cells of the genus Staphylococcus and dependence on their cultivation conditions," Analyst 130, 1543-1550 (2005).

43. D. Mack et al., "The intercellular adhesin involved in biofilm accumulation of Staphylococcus epidermidis is a linear beta-1, 6-linked glucosaminoglycan: purification and structural analysis," J. Bacteriol. 178, 175-183 (1996).

44. Y.-M. Zhang and C. O. Rock, "Membrane lipid homeostasis in bacteria," Nat. Rev. Microbiol. 6, 222-233 (2008).

45. A. Nostro et al., "Effect of alkaline $\mathrm{pH}$ on staphylococcal biofilm formation," APMIS 120, 733-742 (2012).

46. K. C. Rice and K. W. Bayles, "Molecular control of bacterial death and lysis," Microbiol. Mol. Biol. Rev. 72, 85-109 (2008).

Francesco Boschetto is a PhD student at the Kyoto Insititute of Technology, Ceramic Physics Laboratory. He graduated at ' $\mathrm{Ca}$ ' Foscari" University of Venice in science and technologies of nano and biomaterials in 2016. His research focuses on spectroscopic and microscopic studies of the interactions between bioceramic materials and the human body environment.

Tetsuya Adachi is an assistant professor at the Department of Dentistry of the Kyoto Prefectural University of Medicine. He obtained his DDS at the Department of Dentistry, Health Sciences University of Hokkaido, in 2006 and his $\mathrm{PhD}$ at the Department of Immunology, Graduate School of Medicine, University of the Ryukyus in 2012. $\mathrm{He}$ has been a resident in the University Hospital of Kyoto Prefectural University of Medicine between 2011 and 2017.

Satoshi Horiguchi is a PhD student at the Department of Immunology, Kyoto Prefectural University of Medicine since 2016. He graduated from Osaka University Graduate School of Dentistry in 2015.

Danny Fainozzi is a PhD student at the Elettra Synchrotron, Basovizza, Trieste, Italy, where he investigates about "A New Route for the Determination of Protein Structure in Physiological Environment." He got his bachelor degree in physics in 2015 and the master degree in condensed matter physics at the University of Trieste, Italy, in 2017.

Fulvio Parmigiani is a professor of physics at the University of Trieste. Since 2014, he is also a visiting professor at the University of Cologne. A former guest scientist at the IBM Almaden Research Center, California, he has been an affiliate at LBNL, Berkeley, California from 2001 to 2017 . He served as the science director of the FERMI-FEL at Elettra Synchrotron in Trieste from 2004 to 2015. His scientific interests span from nonequilibrium physics of strongly correlated electron systems to low-dimensional materials and high-temperature superconductors. He is a coauthor of about 300 articles, he is an APS fellow.

Elia Marin is an assistant professor at the Kyoto Institute of Technology, Ceramic Physics Laboratory. He is also a specially appointed assistant professor at the Kyoto Prefectural University of Medicine, Graduate School of Medical Science, Department of Dental Medicine. His research focuses on biomaterials' characterization by combined spectroscopic and microscopic techniques and evaluation of the biological response in vitro.

Wenliang Zhu obtained his PhD in materials science from the Kyoto Institute of Technology in 2005 . He became an assistant professor and then an associate professor at the Osaka University Medical School. Currently, he is an associate professor at the Ceramic Physics Laboratory of the Kyoto Institute of Technology. His main research field concerns the development and application of high resolution photo- and electro-stimulated spectroscopies for quantitative analysis of structural, mechanical and chemical properties in singlecrystalline and polycrystalline ceramics.

Bryan J. McEntire is a chief technology officer at Amedica Corporation. He received his BS (cum laude) and MBA degrees from the University of Utah and his PhD from the Kyoto Institute of Technology. He has more than 40 years of industrial experience in the development and manufacturing of advanced ceramics. $\mathrm{He}$ is a coauthor of over 65 peer-reviewed publications and holds four patents. He is a fellow of the American Ceramic Society.

Toshiro Yamamoto obtained both his DDS and $\mathrm{PhD}$ at the Department of Dentistry of the Osaka Dental University in 1995. He has been a resident in the University Hospital of Kyoto Prefectural University of Medicine from 1995 to 2001, where he presently is a lecturer and deputy chief doctor since 2001.

Narisato Kanamura is an associate professor and a chief doctor at the Kyoto Prefectural University of Medicine since the year 2001. He obtained his PhD at the Department of Dentistry, Asahi University, in 1984. He has previously been appointed as a lecturer at the Kyoto Prefectural University of Medicine between 1992 and 2001. His research interests mainly focus of Periodontal Medicine and Tissue Engineering.

Osam Mazda is a professor at the Department of Immunology, Kyoto Prefectural University of Medicine since 2011. He previously was a professor at the Department of Microbiology and Immunology of the same university. He has also been PRESTO researcher until 2012 under the Japan Science and Technology Agency. Since 1993 , he has been a research fellow of the Japanese Society for Promotion of Science.

Eriko Ohgitani obtained her bachelor in veterinary medicine in 1979 at Nihon University. In 1997, she obtained her PhD in medicine at the Department of Microbiology of Kyoto Prefectural University of Medicine. She worked between 1979 and 1984 in a Veterinary Clinic and from 1997 until 2005 as a researcher at Louis Pasteur Center for Medical Research. She is an assistant professor since 2005 at the Department of Immunology, Kyoto Prefectural University of Medicine.

Giuseppe Pezzotti is a vice president and a professor of the Ceramic Physics Laboratory of the Kyoto Institute of Technology. He also serves as a guest professor at the Department of Orthopedics of Tokyo Medical University, as an adjunct professor at the Department of Immunology of the Kyoto Prefectural University of Medicine, and as an invited professor at the Center of Advanced medical Engineering and Informatics of Osaka University. He holds three PhD degrees in engineering (Materials Science from Osaka University), medical science (Orthopedics from Tokyo Medical University), and physical science (Solid State Physics from Kyoto University). He is author/ coauthor of about 620 scientific papers, 8 papers, and 1 book as a single author. 